\title{
Renk açma ve vernikleme işleminin bazı ağaç malzemelerin alev kaynaklı yanma özelliklerine etkileri
}

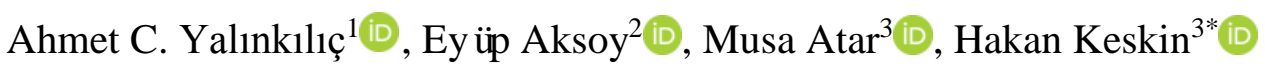

\section{$\ddot{\mathbf{O} z}$}

$\mathrm{Bu}$ çalışma, renk açma ve vernikleme işleminin bazı ağaç malzemelerde alev kaynaklı yanma özelliklerine etkilerini belirlemek amacıyla yapılmıştır. Bu maksatla, Doğu kayını (Fagus orientalis Lipsky), Sapsız meşe (Quercus petraea Liebl.) ve sarıçam (Pinus sylvestris Lipsky) odunlarından ASTM D 358'e göre hazırlanan örneklere, \% 18'lik $\mathrm{NaOH}+\mathrm{H}_{2} \mathrm{O}_{2}$, $\mathrm{NaOH}+\mathrm{Ca}(\mathrm{OH})_{2}+\mathrm{H}_{2} \mathrm{O}_{2}, \mathrm{Na}_{2} \mathrm{~S}_{2} \mathrm{O}_{5}+\mathrm{H}_{2} \mathrm{C}_{2} \mathrm{O}_{4}, \mathrm{NaSiO}_{3}+\mathrm{H}_{2} \mathrm{O}_{2}, \mathrm{KMnO}_{4}+\mathrm{Na}_{2} \mathrm{~S}_{2} \mathrm{O}_{5}+\mathrm{H}_{2} \mathrm{O}_{2}$ çözelti grupları ile renk açma işlemi yapılmıştır. Renk açma işlemi yapılmış örneklere ASTM D 3023'e göre su bazlı, sentetik, poliüretan ve akrilik vernikler uygulanmış ve alev kaynaklı yanma özellikleri ASTM E 160-50 esaslarına göre belirlenmiştir. Sonuç olarak; ağaç malzeme, renk açma çözeltisi ve vernik etkileşimlerine göre; alev kaynaklı yanma sıcaklıkları $\left({ }^{0} \mathrm{C}\right)$ sırasıyla en yüksek; III+R3+Sb'de (473.9), III+R1+Sb'de (639.0), II+R3+St'de (440.0), en düşük; I+R3+Pü'de (188.2), II+R1+Av'de (374.9), I+R1+Sb'de (58.77) çıkmıştır. Bu değerlere göre; renk açma çözeltilerinin, ağaç malzeme ve verniklerin yanmayı artırıcı etkilerini azalttığı söylenebilir. Buna göre yangın riski söz konusu olan kullanım yerlerinde; sapsız meşe+R3 çözeltisi+Akrilik vernik şeklindeki kombinasyon önerilebilir.

Anahtar kelimeler: Renk açma, vernikleme, alev kaynaklı yanma, ağaç malzemeler

\section{Impacts of the bleaching and varnishing process on the flame sources combustion properties of some wood materials}

\section{Abstract}

The aim of this study was to investigate the impact of bleaching and varnishing process on the flame sources combustion properties of some wood materials. For this purpose, Oriental beech (Fagus orientalis Lipsky), European oak (Quercus petraea Liebl.) and Scots pine (Pinus sylvestris Lipsky) wood samples prepared in accordance with ASTM D 358. Bleaching process was carried out with the group, $18 \% \mathrm{NaOH}+\mathrm{H}_{2} \mathrm{O}_{2}, \mathrm{NaOH}+\mathrm{Ca}(\mathrm{OH})_{2}+\mathrm{H}_{2} \mathrm{O}_{2}, \mathrm{Na}_{2} \mathrm{~S}_{2} \mathrm{O}_{5}+\mathrm{H}_{2} \mathrm{C}_{2} \mathrm{O}_{4}$, $\mathrm{NaSiO}_{3}+\mathrm{H}_{2} \mathrm{O}_{2}, \mathrm{KMnO}_{4}+\mathrm{H}_{2} \mathrm{O}_{2}+\mathrm{Na}_{2} \mathrm{~S}_{2} \mathrm{O}_{5}$ solution. Samples of bleaching was carried out in ASTM D 3023 by water-based, synthetic, polyurethane and acrylic varnishes have been implemented and flame sources combustion properties of ASTM E 160-50, was determined according to the principles. As a result, considering the interaction of wood material, bleaching solution and varnish type, flame sources temperature $\left({ }^{\circ} \mathrm{C}\right)$ were the highest; III+R3+Sb (473.9), $\mathrm{III}+\mathrm{R} 1+\mathrm{Sb}$ (639.0), II+R3+St (440.0) the lowest, I+R3+Pü (188.2), II+R1+Av (374.9), I+R1+Sb (58.77). According to these values; It can be said that the bleaching solutions reduce the combustion effects of wood materials and varnishes. Accordingly, in places where there is a risk of fire; can be recommended combination without European oak + R3 solution + Acrylic varnish.

Keywords: Bleaching, varnishing, flame sources combustion, wood materials 


\section{Giriș}

Ahşap malzeme; higroskopik, heterojen ve anizotropik yapıda olması dolayısıyla diğer endüstriyel malzemelere göre üstün özelliklere sahiptir. Ahşabın bu üstün teknolojik özellikleri geniş kullanım alanına sahip olmasını sağlamaktadır. Tüketim miktarının artması ve orman alanlarının gitgide azalması üretilen ahşap malzemenin uzun süre kullanılmasını zorunlu kılmaktadır. Bitkisel (mantar) ve hayvansal (böcek, kurt, termit vb.) zararlılar ile ateşe ve boyut değiştirmelerine karşı odunu kurumak için iç yapısındaki boşluklara kimyasal madde yerleştirerek ağaç malzemenin ömrünün uzatılması işleminin yapılması zorunlu hale getirmiştir. Ahşap malzemeyi biyotik ve abiyotik etkilere karşı korumak için, kurutma, emprenye ve üst yüzey işlemlerinin uygulanması gerekmektedir (Örs ve Keskin, 2008, Highley ve Kicle, 1990). Ağaç malzeme yüzeylerini harici etkilerden korumak ve doğal görüntüsünü belirgin hale getirmek amacıyla en fazla kullanılan koruyucu örtü gereçleri verniklerdir (Sönmez, 1989).

A ğaç türlerinin içerisindeki uçucu maddelerden dolayı odunun kendine has bir kokusu ve tadı, yoğunluk farklılığı nedeni ile ışınların farklı yansıması ile farklı rengi ve parlaklığı, lif yapısı vb. gibi fiziksel (estetik) karekteristik özellikleri farklıdır. Ahşap malzemede renk bozulmaları canlı odunda yaralanma, ölü budak oluşumu, mikroorganizma ve mantar hastalıkları vb. biyotik sebepler yanında odundaki bazı kimyasal maddelerin oksidasyonu ve tanenli odunların metallerle teması ile oluşan renklenmeler ile meydana gelmektedir (Banks ve Miller, 1982).

Ağaç işlerinde renk, ölçü, biçim, form, fonksiyon vb. kadar önemlidir. Doğal halde iken ağaç malzemenin rengi çoğu zaman bu tür ihtiyaçlara cevap vermeyebilir. Üst yüzey işlemleri yapmadan önce ahşap yüzeylerinde renk açma işlemi ile istenen renk uyumu sağlanabilir. Renk açma işlemi ve emprenye etme ağaç malzeme yapısına tesir etmekte, sertlik, parlaklık ve renk özelliklerine tesir etmektedir. Renk açma, kimyasal bir çözelti ile ağaç malzeme yüzeyi renginin daha açık hale getirilmesidir. Mobilya endüstrisinde meşe ve kestane gibi bazı ağaç odunlarına üst yüzey işlemleri ile birlikte renk açma işlemi uygulanmaktadır (Edwin ve Carter, 1983).

Özçifçi, (2001) çalışmasında, sapsız meşede (Quercus sessiliflora Salisb.) (Oksalik asit $\left(\mathrm{C}_{2} \mathrm{O}_{4} \mathrm{H}_{2}\right)$, sodyum hidroksit $(\mathrm{NaOH})$, hidrojen peroksit $\left(\mathrm{H}_{2} \mathrm{O}_{2}\right)$, amonyak $\left(\mathrm{NH}_{3}\right)$ ve hidroklorik asit $(\mathrm{HCl})$ ile Renk açma işıleminin $\mathrm{CO}_{2}$ miktarı (ppm), yanma çeşidi bakımından en yüksek kendi kendine yanmada $(6,5)$, en düşük alev kaynaklı yanmada $(5,1)$ bulunmuştur.

Fidan ve ark. (2016), çalışmalarında, Tanalith-E ve Wolmanit-CB ile emprenye edilmiş kestane (Castanea sativa Mill.) odunlarına su bazlı ve sentetik vernik uygulandıktan sonra bir yıl dış hava şartlarında bekletilmişlerdir. Deney örneklerin yanma özelliklerinde $\mathrm{CO}_{2}$ miktarı (ppm) yanma çeşidi bakımından en yüksek kendi kendine yanmada $(19,18)$, en düşük kor hali yanmada $(10,89)$, vernik çeşidi bakımından en yüksek sentetik vernikte kendi kendine yanmada $(19,82)$ en düşük su bazlı vernikte alev kaynaklı yanmada $(8,66)$ bulunduğu bildirilmiştir.

Uysal ve Özcifçi, (2000), yaptığ çalışmalarında oksalik asit $\left(\mathrm{C}_{2} \mathrm{O}_{4} \mathrm{H}_{2}\right)$, sodyum hidroksit $(\mathrm{NaOH})$, Hidrojen peroksit $\left(\mathrm{H}_{2} \mathrm{O}_{2}\right)$, amonyak $\left(\mathrm{NH}_{3}\right)$, hidroklorik asit $(\mathrm{HCl})$ ile rengi açılan Doğu kayını yanma özelliğinde en fazla $\mathrm{CO}_{2}$ değişim miktarı I. $\left(\mathrm{C}_{2} \mathrm{O}_{4} \mathrm{H}_{2}\right)^{\prime}$ de elde edildiği tespit edilmiştir. Çalışma sonucunda, $\mathrm{CO}_{2}$ değişimi bakımından renk açma maddesi çeşidinin etkili olduğu ifade edilmiştir.

Yaşar ve Atar, (2017), çalışmalarında Tanalith-E ve Wolmanit-CB ile emprenye edilen sarıçam (Pinus sylvestris Lipsky), sapsız meşe (Quercus petraea Liebl.) ve Doğu kayını (Fagus orientalis Lipsky) odunları sentetik ve su bazlı vernik ile kaplandıktan sonra yanma testlerine tabi tutulmuştur, Örneklerin yanma özelliklerinde $\mathrm{CO}_{2}$ miktarı (ppm) yanma çeşidi bakımından en yüksek kendi kendine yanmada $(16,4)$, en düşük kendi kendine yanmada $(1,4)$, sentetik 
vernikte en yüksek kendi kendine yanmada $(17,5)$ en düşük su bazlı vernikte alev kaynaklı yanmada (5.4) bulunduğu bildirilmiştir.

$\mathrm{Bu}$ çalışmada, renk açıcı maddelerin ve verniklerin ağaç malzemenin alev kaynaklı yanma özellikleri üzerinde etkisi belirlenmeye çalışılmıştır. Ülkemizde mobilya endüstrisinde yaygın kullanılan ağaç türleri, vernikler ve renk açma maddelerinin etkileşiminin incelenmesi ve bunların imalatçının ve tasarımcının kullanımı için uygun hale getirilmesi araştırmamızın özgün değerini oluşturmaktadır.

\section{Materyal ve Metot}

\subsection{Materyal}

Ağaçişleri endüstrisinde yaygın olarak kullanılması nedeniyle sarıçam (Pinus sylvestris Lipsky), Doğu kayını (Fagus orientalis Lipsky), sapsız meşe (Quercus petreae Lipsky) odunları deney materyali olarak seçilmiştir. Deney örneklerinde kullanılan ahşap malzeme TS 1476 standardı esaslarına uygun olarak, düzgün lifli, ardaksız, budaksı, mikroorganizma, mantar ve böcek zararlılarına maruz kalmamış ağaç malzemeler, Ankara - Siteler bölgesindeki kereste işletmelerinden temin edilmiştir.

\subsubsection{Vernikler}

Deney örneklerinin verniklenmesinde tek bileşenli su bazlı, sentetik, akrilik ve poliüretan vernik kullanılmıştır (Bankowsky ve Eichletoer, 1993).

Su bazlı vernik; renksiz, kokusuz ve ağaç malzemenin doğal rengini değiştirmeyen özelliktedir. Kuruması kimyasal olup, dönüşümsüz katmanlar verir. Birden fazla kat aynı günde uygulanabilir. Temizlik maddeleri, yağlar, hardal, şarap ve sirkeye karşı dayanıklıdır. Su bazlı vernik uygulanacak yüzeyler zımparalanarak toz, kir, yağ vb. arındırılmalı ve yüzeyler kuru olmalidir.

Sentetik vernik, oluşumunu tamamlamış ve polimerleşmesi yarım bırakılmış olarak iki tipte üretilmektedir. Oluşumunu tamamlamış sentetik reçineler nitroselüloza benzer ve fîziksel kuruma yaparlar. Polimerleşmesi yarım bırakılmış sentetik reçinelerde yağlı bir alkid kullanılmaktadır. Strenal alkid ve üretan alkid bu amaçla kullanılır. Bunlarda, polimerizasyona ya da oksidasyona dayalı bir kuruma şekli görülür ve dönüşümsüzdür. Sentetik vernikte çözücü olarak terebentin kullanılmaktadır. Kurumayı hızlandırmak için oksijen verme yeteneğindeki metal sabunları, katalizör olarak kullanılır (Sönmez, 1989).

Akrilik vernik, akrilik reçineden üretilen çift kompenentli bir verniktir. Ağaçişlerinde her çeşit masif ve kaplama ile özellikle renk değişikliği ve sararmanın istenmediği kaplamalarda kullanılmak üzere geliştirilmiş̧ir. Ayrıca yaşlanma sonucu bozulmaya dayanıklı, su beyazı orijinal rengi, yüksek sıcaklığa dayanıklı, elektrik akımına karşı dirençli olup, pigment ilavesi yapıldığında dayanıklı ve esnek filmler verir (Budakçı, 2003).

\subsubsection{Renk açma çözeltileri}

Renk açma işleminde kullanılan çözeltilerin teknik özellikleri aşağıda verilmiştir (Atar 1999).

Sodyum hidroksit $(\mathrm{NaOH})$; beyaz kristal halde olup, çözeltisi kuvvetli reaksiyon gösterir. $18^{\circ} \mathrm{C}$ sıcaklıkta, \%52 oranında çözünür ve bu esnada ısı verir. Çözünme 1 sıs1 $9.9 \mathrm{kcal} / \mathrm{mol}$, erime noktasi $322^{\circ} \mathrm{C}$, yoğunluğu $1.2 \mathrm{~g} / \mathrm{cm}^{3}$, normal çözeltinin $\mathrm{pH}$ derecesi 14'tür. Higroskopik bir madde olup, su ve alkolde kolayca çözünür.

Hidrojen peroksit $\left(\mathrm{H}_{2} \mathrm{O}_{2}\right)$; perhidrol olarak bilinen çözelti, renksizdir. Molekül ağırlığı, $34 \mathrm{~g} / \mathrm{mol}$, erime noktas $-26^{\circ} \mathrm{C}$, kaynama noktas $107^{\circ} \mathrm{C}$, bir litredeki ağırlığ ise, $1.12 \mathrm{~kg}$ ' dır. 
Sodyum silikat $\left(\mathrm{NaSiO}_{3}\right)$; genellikle alkasil olarak bilinen bu çözelti, suda çözünür ve ince toz haline getirilmiş kuvarsın soda ile birlikte eritilmesiyle elde edilir. Molekül ağırlı̆̆ $1,22.9$ $\mathrm{g} / \mathrm{mol}$, erime noktas $1088^{\circ} \mathrm{C}$ dir.

Kalsiyum hidroksit $\left(\mathrm{Ca}(\mathrm{OH})_{2}\right)$; sönmüş kireç olarak bilinen kalsiyum hidroksit, ince beyaz bir tozdur. Molekül ağırlı̆̆ $1,74 \mathrm{~g} / \mathrm{mol}, 20^{\circ} \mathrm{C}$ 'de 1 litre suda $1.7 \mathrm{~g}$ çözünebilmektedir.

Asetik asit $\left(\mathrm{CH}_{3} \mathrm{COOH}\right)$; piyasada ethenoik asit olarak bilinir ve beyaz, renksiz sıv1 halinde satılır. Molekül ağırlığı, $60 \mathrm{~g} / \mathrm{mol}$, ergime noktası $16.5^{\circ} \mathrm{C}$, yoğunluğu ise, $1.04 \mathrm{~g} / \mathrm{mol}$ olup renk açma işleminde hem renk açıcı hem de nötrleştirme gereci olarak kullanılır.

Sodyum disülfit $\left(\mathrm{Na}_{2} \mathrm{~S}_{2} \mathrm{O}_{5}\right)$; higroskopik bir madde olup beyaz renkli toz halinde piyasada bulmak mümkündür. Yoğunluğu $1.5 \mathrm{~g} / \mathrm{cm}^{3}, \% 40 ' 11 \mathrm{k} \mathrm{Na} 2 \mathrm{~S}_{2} 0_{5}$ çözeltisi hafif asidik reaksiyon gösterir, molekül ağırlığı $190 \mathrm{~g} / \mathrm{mol}$, erime noktası $170^{\circ} \mathrm{C}$ olup $20^{\circ} \mathrm{C}$ sicaklıkta $54 \mathrm{~g} / 100 \mathrm{ml}$ çözünür.

Oksalik asit $\left(\mathrm{H}_{2} \mathrm{C}_{2} \mathrm{O}_{4}\right)$; renksiz prizmalar halinde olup, $100 \mathrm{~g}$ suda $20^{\circ} \mathrm{C}$ de $10 \mathrm{~g}$ çözünür. Sudaki çözeltisinin reaksiyonu kuvvetli asittir. Molekûl ağırlı̆̆ 126,07 g/mol, erime noktası $101^{\circ} \mathrm{C}$, kaynama noktas $150^{\circ} \mathrm{C}$, yoğunluğu $1,653 \mathrm{gr} / \mathrm{mol}$ olup, orta derecede kuvvetli asit özelliğindedir.

Potasyum permanganat $\left(\mathrm{KMnO}_{4}\right)$; piyasada kat1 ve siv1 halde bulunur, oksitlenebilme özelliği yanında zehirli olup ucuz ve kolay temin edilebilmektedir. Molekûl ağırlığı $158 \mathrm{~g} / \mathrm{mol}$, erime noktas $150^{\circ} \mathrm{C}$ olup, $20^{\circ} \mathrm{C}$ sicaklıkta bir litre suda $65 \mathrm{~g}$ çözünür.

\subsection{Metot}

\subsubsection{Deneme numunelerinin hazırlanması}

Denemelerde kullanılan ağaç malzemeler TS 2471 standardı esaslarına göre tamamen tesadüfî̀ metotla birinci sınıf ağaç malzemeden düzgün lifli, budaksız, çatlaksız, reaksiyon odunu bulunmayan, yoğunluk farkı olmayan, mantar ve böcek zararlılarına uğramamış olmalarına özen gösterilmiş ve yıllık halkalar yüzeye dik gelecek șekilde ve diri odun kısımlarından hazırlanmıştır. Deney örnekleri $20 \pm 2^{\circ} \mathrm{C}$ sıcaklık ve $\% 65 \pm 3$ bağıl nem şartlarında \%12 rutubete ulaşıncaya kadar bekletilmiştir (TS 2471). Hava kurusu rutubetteki örnekler ASTM E 160-50 esaslarına göre 1,3x1,3x7,6cm ölçülerinde yanma deney örnekleri hazırlanmıştır. Denemelerde, 3 ağaç türü, 4 vernik çeşidi +1 kontrol, 5 renk açma çözeltisi +1 kontrol, 3 grup ve her grupta 24 adet olmak üzere $(3 \times 5 \times 6 \times 3 \times 24)$ toplam 6480 adet deney örneği kullanılmıştır.

\subsubsection{Renk açma işlemi}

Renk açma işlemi için hazırlanan deney örnekleri \%18'lik $\mathrm{NaOH}+\mathrm{H}_{2} \mathrm{O}_{2}$, $\mathrm{NaOH}+\mathrm{Ca}(\mathrm{OH})_{2}+\mathrm{H}_{2} \mathrm{O}_{2}, \quad \mathrm{NaSiO}_{3}+\mathrm{H}_{2} \mathrm{O}_{2}, \quad \mathrm{Na}_{2} \mathrm{~S}_{2} \mathrm{O}_{5}+\mathrm{H}_{2} \mathrm{C}_{2} \mathrm{O}_{4}, \quad \mathrm{KMnO}_{4}+\mathrm{Na}_{2} \mathrm{~S}_{2} \mathrm{O}_{5}+\mathrm{H}_{2} \mathrm{O}_{2}$ çözelti grupları ile renk açma işlemine tabi tutulmuştur. Renk açıcı olarak, yedi ayrı kimyasal madde ile 5 çözelti grubu oluşturulmuştur (Çizelge 1).

Çizelge 1. Renk açmada kullanılan çözelti grupları

\begin{tabular}{|c|c|}
\hline Kimyasal Çözeltiler & Nötrleştirme Maddeleri \\
\hline $\mathrm{NaOH}+\mathrm{H}_{2} \mathrm{O}_{2}(\mathrm{R} 1)$ & \multirow{5}{*}{$\begin{array}{l}\text { Destile } \mathrm{Su} \\
\text { Asetik Asit }\left(\mathrm{CH}_{3} \mathrm{COOH}\right)\end{array}$} \\
\hline $\mathrm{NaOH}+\mathrm{Ca}(\mathrm{OH})_{2}+\mathrm{H}_{2} \mathrm{O}_{2}(\mathrm{R} 2)$ & \\
\hline $\mathrm{NaSiO}_{3}+\mathrm{H}_{2} \mathrm{O}_{2}(\mathrm{R} 3)$ & \\
\hline $\mathrm{Na}_{2} \mathrm{~S}_{2} \mathrm{O}_{5}+\mathrm{H}_{2} \mathrm{C}_{2} \mathrm{O}_{4}(\mathrm{R} 4)$ & \\
\hline $\mathrm{KMnO}_{4}+\mathrm{Na}_{2} \mathrm{~S}_{2} \mathrm{O}_{5}+\mathrm{H}_{2} \mathrm{O}_{2}(\mathrm{R} 5)$ & \\
\hline
\end{tabular}


Renk açmada kullanılacak kimyasal maddeler, özelliklerine göre, ağırlıkça (Mg) ya da hacimce (Vml) \% 18'lik hazırlanmıştır. Bu amaçla, katı halde olanlar;

$$
M_{g}=\frac{M_{c ̧} \cdot \% M / M}{\% S}
$$

$M_{g} \quad$ : İstenen çözelti miktarı (gr),

$M_{c ̧} \quad$ : Hazırlanması istenen çözelti miktarı (gr)

$\% M / M$ : İstenen çözeltinin ağırlıkça yüzdesi,

$\% S \quad$ : Kimyasal maddenin safsizlık oranı (\%)

Sivı halde olanlar;

$$
V_{m l}=\frac{V_{c} \cdot \% V / V}{\% S \cdot d}
$$

$V_{m l} \quad:$ İstenen çözelti miktarı (ml),

$V_{c} \quad:$ Hazırlanması istenen çözelti miktarı $(\mathrm{ml})$

$\% V / V$ : İstenen çözeltinin hacimce yüzdesi,

d : Çözeltinin yoğunluğu (gr/ $/ \mathrm{cm}^{3}$ ), eşitlikleri kullanılmıştır (Atar 1999).

Renk açma çözeltileri, deney örnekleri yüzeylerine sünger ile ilk önce liflere paralel daha sonra liflere dik ve tekrar liflere paralel yönde olarak tatbik edilmiştir. Çözeltiyi oluşturan maddeler ayrı ayrı sürülmüş, ilk sürülen maddenin etkisinin artması için yaklaşık 2 dakika bekledikten sonra ikinci çözelti uygulanmıştır. Deneylerde kullanılan 7 renk açıcı kimyasalın pH değerleri pH kâğgdı ile ölçülerek Çizelge 2'de verilmiştir.

Çizelge 2. Renk açıcı kimyasalların pH değerleri

\begin{tabular}{|l|c|}
\hline Renk Aç1c1 Kimyasal & $\mathrm{pH}\left(25^{\circ} \mathrm{C}\right)$ \\
\hline $\mathrm{NaOH}$ & 14 \\
\hline $\mathrm{H}_{2} \mathrm{O}_{2}$ & 4 \\
\hline $\mathrm{Na}_{2} \mathrm{~S}_{2} \mathrm{O}_{5}$ & 5 \\
\hline $\mathrm{Ca}(\mathrm{OH})_{2}$ & 10 \\
\hline $\mathrm{H}_{2} \mathrm{C}_{2} \mathrm{O}_{4}$ & 2 \\
\hline $\mathrm{NaSiO}_{3}$ & 12 \\
\hline $\mathrm{KMnO}_{4}$ & 12 \\
\hline
\end{tabular}

Renk açma işlemi tamamlandıktan sonra etki derinliğini arttırmak için oda sıcaklığında 2 gün bekletildikten sonra asetik asit ve bol su ile nötrleştirme işlemi yapılmıştır. $\mathrm{Bu}$ işlemden sonra, örneklerinin hava kurusu (\%12) rutubete ulaşması sağlanmıştır. Vernikleme işleminden önce yüzeyler hafifçe zımparalanmıştır.

\subsubsection{Vernikleme işlemi}

Deney örneklerine renk açma işlemi uygulandıktan sonra üst yüzey işlemlerine hazır hale getirilebilmesi için iklimlendirme dolabında $20 \pm 2{ }^{\circ} \mathrm{C}$ sıcaklık ve $\% 65 \pm 3$ bağıl nem şartlarında ağırlığı değişmez hale gelinceye kadar bekletilmiştir. Numunelerin verniklenmesi ASTM D 3023 standardı esaslarına göre yapılmıştır. Su bazlı vernik uygulaması, \%10 su karıştırılarak yüksek basınçlı tabanca ile 3 kat olarak uygulanıp $\% 10$ rutubet için $20 \pm 2^{\circ} \mathrm{C}$ sicaklık $\% 65 \pm 3$ bağıl nem şartlarında 3 hafta süreyle kurumaya bırakılmıştır. Sentetik vernik uygulaması, deney 
örneklerine firça ile 3 kat olarak uygulanmıştır. Örnekler, vernik sürme işleminden sonra $20 \pm 2^{\circ} \mathrm{C}$ sıcaklık ve $\% 65 \pm 3$ bağıl nem şartlarında kurumaya bırakılmıştır. Örnek yüzeylerine akrilik ve poliüretan vernik uygulaması fırça ile 3 kat uygulanmıştır.

\subsubsection{Alev kaynaklı yanma deneyi}

Renk açma işlemi yapılmış ve yapılmamış vernikli ve verniksiz ağaç malzemede yanma özellikleri ASTM E 160-50 esaslarına uyularak Şekil 1'de gösterilen yanma test cihazı kullanılmıştır. Buna göre; yanma deneyi öncesi her örnek grubu tartılarak aletteki tel sehpaya istiflenmiştir. Her katta bulunan örnekler alt ve üstündeki katlarda bulunanlara dikey konumda yerleştirilmiştir. Alev kaynağı istifin altına merkezlenerek 3 dakika süreyle alev kaynaklı yanma sürdürülmüştür (Aşc1 ve Keskin, 2019).

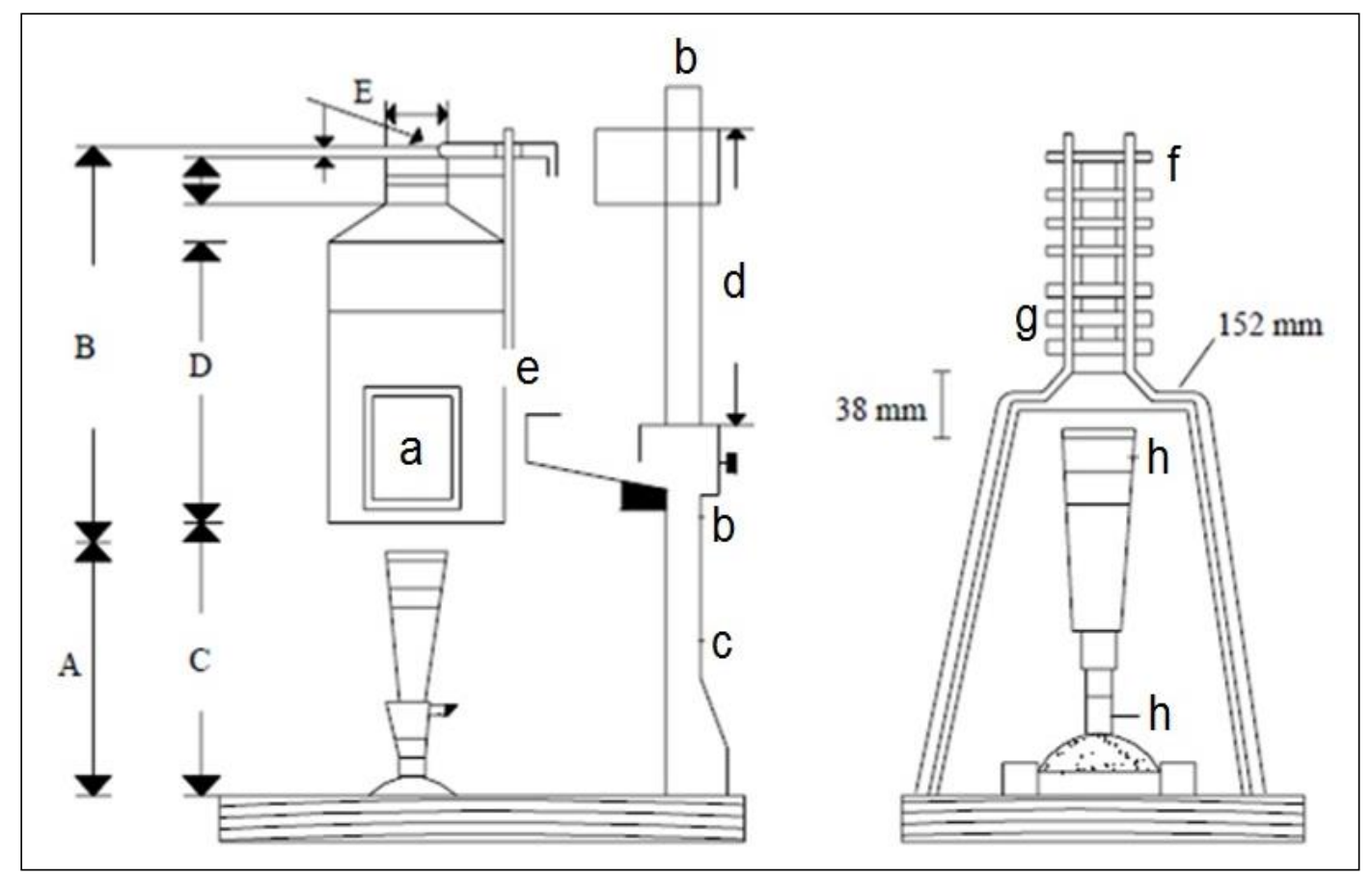

Şekil 1. Yanma test cihazı

a. Mika cam b. Kızak sonu c. Bek rehberi d. Kızak e. Potansiyometre veya Milivoltmetre giriși f. Odun örnekleri g. Tel kafes h. Bek (maker tipi) A. $270 \mathrm{~mm}$. B. $430 \mathrm{~mm}$. C. $295 \mathrm{~mm}$. D. $305 \mathrm{~mm}$. E. $38 \mathrm{~mm}$. (ASTM E 160-50)

\subsection{Data Analizi}

Verilerin değerlendirilmesinde çoklu varyans analizi kullanılmıştır. Varyans analizinde F testine göre gruplar arası fark önemli çıktığında, Duncan testi ile ortalama değerler arasındaki fark karşılaştırılmıştır.

\section{Bulgular ve Tartışma}

Alev kaynaklı yanmada, sıcaklığa ilişkin ortalama değerler Çizelge 3'de, ağaç türü, renk açma çözeltisi ve vernik çeşidinin alev kaynaklı yanma sıcaklığına etkilerine ilişkin varyans analizi sonuçları Çizelge 4'de verilmiştir. 
Çizelge 3. Alev kaynaklı yanmada yanma sıcaklık değerleri $\left({ }^{\circ} \mathrm{C}\right)$

\begin{tabular}{|c|c|c|}
\hline Ăgaç türü & $\bar{X}$ & HG* \\
\hline Doğu kayını (I) & 356.3 & A \\
\hline Sapsız meşe (II) & 316.1 & $\mathrm{~B}$ \\
\hline Sarıçam (III) & 364.9 & A \\
\hline Renk açma çözeltileri & $\bar{X}$ & HG** \\
\hline Kontrol (Ko) & 353.5 & $\mathrm{~B}$ \\
\hline $\mathrm{NaOH}+\mathrm{H}_{2} \mathrm{O}_{2}(\mathrm{R} 1)$ & 382.3 & A \\
\hline $\mathrm{NaOH}+\mathrm{Ca}(\mathrm{OH})_{2}+\mathrm{H}_{2} \mathrm{O}_{2}(\mathrm{R} 2)$ & 337.7 & B \\
\hline $\mathrm{NaSiO}_{3}+\mathrm{H}_{2} \mathrm{O}_{2}(\mathrm{R} 3)$ & $\begin{array}{l}308.6 \\
3500\end{array}$ & $\mathrm{C}$ \\
\hline $\mathrm{NaHSO}_{3}+\mathrm{H}_{2} \mathrm{C}_{2} \mathrm{O}_{4}(\mathrm{R} 4)$ & $\begin{array}{l}550.0 \\
342.4\end{array}$ & B \\
\hline $\mathrm{KMnO}_{4}+\mathrm{NaHSO}_{3}+\mathrm{H}_{2} \mathrm{O}_{2}$ (R5) & & $\mathrm{B}$ \\
\hline Vernikler & $\bar{X}$ & $\mathbf{H G}^{* * *}$ \\
\hline Kontrol (K) & 371.7 & A \\
\hline Su bazlı vernik (Sb) & 329.4 & $\mathrm{BC}$ \\
\hline Sentetik vernik $(\mathrm{St})$ & 358.2 & $\mathrm{~A}$ \\
\hline Poliüretan vernik (Pü) & 319.5 & $\mathrm{C}$ \\
\hline Akrilik vernik (Av) & & $\mathrm{AB}$ \\
\hline
\end{tabular}

$\mathrm{HG}=$ Homojenlik grupları, ${ }^{*}$ LSD:18.87, $* *$ LSD:26.68, $* * *$ LSD:24.36

Alev kaynaklı yanmada yanma sıcaklığı; en yüksek sarıçam R1 ve sentetik vernikte, en düşük sapsız meşe, R3 ve poliüretan vernikte bulunmuştur. Renk açma çözeltilerinden R1 hariç diğerleri ile vernikler sıcaklığı azaltıcı etki göstermiştir. Buna göre, sapsız meşe, R3 ve poliüretan vernik yanmayı önleyici etki göstermiştir. Bu durum alevli yanma riski olan yerlerde dikkate alınabilir.

Çizelge 4. Ağaç türü, renk açma çözeltisi ve vernik çeşidinin alev kaynaklı yanmada yanma sıcaklığına etkilerine ilişkin varyans analiz sonuçları

\begin{tabular}{|l|c|l|l|l|l|}
\hline $\begin{array}{c}\text { Varyans } \\
\text { Kaynağı }\end{array}$ & $\begin{array}{c}\text { Serbestlik } \\
\text { Derecesi }\end{array}$ & \multicolumn{1}{|c|}{$\begin{array}{c}\text { Kareler } \\
\text { Toplamı }\end{array}$} & $\begin{array}{c}\text { Kareler } \\
\text { Ortalaması }\end{array}$ & \multicolumn{1}{|c|}{$\begin{array}{c}\text { F } \\
\text { Değeri }\end{array}$} & $\begin{array}{c}\text { P<0,05 } \\
\text { SIG. }\end{array}$ \\
\hline Faktör A & 2 & 122270.536 & 61135.268 & 14.7958 & 0.0000 \\
Faktör B & 4 & 97410.876 & 24352.719 & 5.8938 & 0.0002 \\
AB & 8 & 43533.412 & 5441.676 & 1.3170 & 0.2375 \\
Faktör C & 5 & 129127.790 & 25825.558 & 6.2502 & 0.0000 \\
AC & 10 & 46070.546 & 4607.055 & 1.1150 & 0.3532 \\
BC & 20 & 859461.903 & 42973.095 & 10.4002 & 0.0000 \\
ABC & 40 & 727741.155 & 18193.529 & 4.4031 & 0.0000 \\
Hata & 180 & 743748.391 & 4131.936 & & \\
Toplam & 269 & 2769364.608 & & & \\
\hline
\end{tabular}

Ağaç türü, renk açma çözeltisi ve vernik çeşidinin alev kaynaklı yanmada yanma sıcaklığına etkileri vernik ağaç etkileşimi hariç istatiksel anlamda önemli çıkmıştır $(\alpha=0,05)$. Farklılığın hangi gruplar arasında önemli olduğunu belirlemek için yapılan DUNCAN testi sonuçları Çizelge 5'de verilmiştir. 
Çizelge 5. Alev kaynaklı sıcaklığa ilişkin Duncan testi sonuçları

\begin{tabular}{|c|c|c|c|c|c|c|c|c|}
\hline $\begin{array}{l}\text { İşlem } \\
\text { Çeşidi }\end{array}$ & $\bar{X}$ & HG & $\begin{array}{l}\text { İşlem } \\
\text { Çeşidi }\end{array}$ & $\bar{X}$ & HG & $\begin{array}{l}\text { İşlem } \\
\text { Çeşidi }\end{array}$ & $\bar{X}$ & *HG \\
\hline $\mathrm{I}+\mathrm{R} 4$ & 492.0 & $\mathrm{a}$ & $\mathrm{III}+\mathrm{R} 1+\mathrm{Sb}$ & 395.0 & bcdefghıjk & $\mathrm{III}+\mathrm{R} 5+\mathrm{Av}$ & 302.1 & hijklmno \\
\hline III+R5 & 89.6 & $a b$ & $\mathrm{II}+\mathrm{R} 2+\mathrm{St}$ & 390.4 & bcdefghijk & $\mathrm{II}+\mathrm{R} 2+\mathrm{P} \ddot{\mathrm{u}}$ & 297.9 & 1jklmno \\
\hline II & 484.0 & $a b$ & $\mathrm{II}+\mathrm{R} 5+\mathrm{St}$ & 385.0 & bcdefghijk & $\mathrm{I}+\mathrm{R} 2+\mathrm{P} \ddot{\mathrm{u}}$ & 291.1 & 1jklmno \\
\hline $\mathrm{III}+\mathrm{St}$ & 474.2 & $a b c$ & $\mathrm{III}+\mathrm{R} 2+\mathrm{Pü}$ & 380.8 & bcdefghijk & $\mathrm{II}+\mathrm{R} 3$ & 287.2 & 1jklmno \\
\hline $\mathrm{III}+\mathrm{R} 3+\mathrm{Sb}$ & 473.9 & $a b c$ & $\mathrm{III}+\mathrm{R} 5+\mathrm{Sb}$ & 378.7 & cdefghıjk & $\mathrm{III}+\mathrm{R} 3+\mathrm{Av}$ & 284.0 & 1jklmno \\
\hline $\mathrm{I}+\mathrm{R} 2+\mathrm{St}$ & 469.6 & abcd & $\mathrm{I}+\mathrm{R} 3+\mathrm{Sb}$ & 378.7 & cdefghıjk & $\mathrm{III}+\mathrm{R} 1+\mathrm{Pü}$ & 279.3 & 1jklmno \\
\hline $\mathrm{I}+\mathrm{Sb}$ & 464.1 & abcde & III+R4 & 374.0 & cdefghıjk & $\mathrm{III}+\mathrm{R} 4+\mathrm{Av}$ & 277.2 & 1jklmno \\
\hline III+R2 & 463.8 & abcde & $\mathrm{I}+\mathrm{R} 1$ & 373.6 & cdefghıjk & $\mathrm{II}+\mathrm{Sb}$ & 275.2 & 1jklmno \\
\hline $\mathrm{III}+\mathrm{Sb}$ & 463.7 & abcde & $\mathrm{I}+\mathrm{R} 2+\mathrm{Av}$ & 369.1 & cdefghıjk & $\mathrm{I}+\mathrm{R} 4+\mathrm{Sb}$ & 273.9 & 1jklmno \\
\hline III+R3 & 461.9 & abcde & $\mathrm{III}+\mathrm{R} 2+\mathrm{St}$ & 361.4 & cdefghıjk & $\mathrm{I}+\mathrm{R} 1+\mathrm{Sb}$ & 263.5 & 1jklmno \\
\hline I & 460.9 & abcde & $\mathrm{II}+\mathrm{R} 3+\mathrm{Pü}$ & 359.4 & cdefghıjk & $\mathrm{I}+\mathrm{R} 4+\mathrm{Pü}$ & 257.6 & jklmnop \\
\hline III+R1 & 457.5 & abcdef & $\mathrm{III}+\mathrm{R} 4+\mathrm{Pü}$ & 355.2 & cdefghıjk & $\mathrm{II}+\mathrm{R} 5+\mathrm{Av}$ & 257.1 & klmnop \\
\hline $\mathrm{II}+\mathrm{St}$ & 454.7 & abcdefg & $\mathrm{III}+\mathrm{R} 5+\mathrm{Sb}$ & 353.5 & defghıjkl & $\mathrm{II}+\mathrm{R} 3+\mathrm{Av}$ & 256.1 & klmnop \\
\hline III & 452.0 & abcdefg & $\mathrm{III}+\mathrm{R} 3+\mathrm{Pü}$ & 348.7 & defghıjkl & $\mathrm{I}+\mathrm{R} 1+\mathrm{Pu}$ & 249.1 & klmnop \\
\hline II+R5 & & & $\mathrm{II}+\mathrm{R} 2+\mathrm{Av}$ & & & $\mathrm{I}+\mathrm{R} 5+\mathrm{Av}$ & 248.6 & klmnop \\
\hline $\mathrm{I}+\mathrm{R} 2+\mathrm{Sb}$ & 447.7 & abcdefgh & $\mathrm{I}+\mathrm{R} 3+\mathrm{St}$ & 341.5 & efghijklm & $\mathrm{I}+\mathrm{R} 1+\mathrm{Av}$ & 247.4 & Imnop \\
\hline II+R1 & 446.7 & abcdefgh & $\mathrm{I}+\mathrm{R} 4+\mathrm{Sb}$ & 337.8 & efghıjklm & $\mathrm{II}+\mathrm{R} 5+\mathrm{Sb}$ & 242.5 & lmnop \\
\hline $\mathrm{I}+\mathrm{R} 5$ & 445.5 & abcdefgh & $\mathrm{III}+\mathrm{R} 5+\mathrm{St}$ & 337.0 & efghijklm & $\mathrm{II}+\mathrm{R} 3+\mathrm{St}$ & 242.0 & lmnop \\
\hline $\mathrm{II}+\mathrm{R} 5+\mathrm{Pü}$ & 442.9 & abcdefgh & $\mathrm{I}+\mathrm{St}$ & 335.6 & fghijklm & $\mathrm{III}+\mathrm{R} 2+\mathrm{Av}$ & 241.2 & \\
\hline $\mathrm{I}+\mathrm{R} 3+\mathrm{Pü}$ & 437.3 & abcdefgh & $\mathrm{I}+\mathrm{R} 4+\mathrm{St}$ & 335.1 & fghijklm & $\mathrm{II}+\mathrm{R} 4+\mathrm{Av}$ & 229.7 & mnop \\
\hline $\mathrm{I}+\mathrm{R} 1+\mathrm{St}$ & 433.6 & abcdefgh & $\mathrm{II}+\mathrm{R} 1+\mathrm{St}$ & 334.1 & fghijklmn & $\mathrm{II}+\mathrm{R} 1+\mathrm{Sb}$ & 226.3 & nopq \\
\hline $\mathrm{III}+\mathrm{R} 1+\mathrm{St}$ & 432.3 & abcdefgh & $\mathrm{I}+\mathrm{R} 5+\mathrm{P} \ddot{\mathrm{u}}$ & 331.9 & fghijklmn & $\mathrm{I}+\mathrm{P} \ddot{\mathrm{u}}$ & 224.5 & opq \\
\hline $\mathrm{I}+\mathrm{R} 2$ & 417.9 & abcdefgh & $\mathrm{II}+\mathrm{R} 1+\mathrm{Pü}$ & 328.2 & ghijklmn & $\mathrm{II}+\mathrm{R} 4+\mathrm{Sb}$ & 217.0 & $\mathrm{pq}$ \\
\hline $\mathrm{II}+\mathrm{R} 4+\mathrm{Pü}$ & 412.6 & abcdefgh & $\mathrm{I}+\mathrm{R} 5+\mathrm{Sb}$ & 323.3 & ghijklmn & III+Av & 214.2 & $q r$ \\
\hline $\mathrm{I}+\mathrm{R} 5+\mathrm{St}$ & 411.3 & abcdefgh & $\mathrm{II}+\mathrm{Pü}$ & 312.8 & ghijklmn & $\mathrm{II}+\mathrm{R} 1+\mathrm{Av}$ & 206.0 & $q r$ \\
\hline $\mathrm{I}+\mathrm{R} 3$ & 410.6 & abcdefghı & $\mathrm{III}+\mathrm{Pü}$ & 312.4 & ghijklmn & $\mathrm{II}+\mathrm{R} 4$ & 203.7 & rs \\
\hline $\mathrm{II}+\mathrm{R} 2$ & 404.0 & abcdefghı & $\mathrm{II}+\mathrm{R} 4+\mathrm{St}$ & 308.8 & ghijklmn & $\mathrm{III}+\mathrm{R} 1+\mathrm{Av}$ & 203.7 & rs \\
\hline $\mathrm{III}+\mathrm{R} 2+\mathrm{Sb}$ & 401.3 & bcdefghıj & $\mathrm{III}+\mathrm{R} 3+\mathrm{St}$ & 308.6 & ghijklmno & $\mathrm{II}+\mathrm{R} 2+\mathrm{Sb}$ & 196.1 & st \\
\hline $\mathrm{I}+\mathrm{R} 4+\mathrm{Av}$ & 396.9 & bcdefghıj & $\mathrm{II}+\mathrm{R} 3+\mathrm{Sb}$ & 307.4 & ghijklmno & $\mathrm{I}+\mathrm{R} 3+\mathrm{P} \ddot{\mathrm{u}}$ & 188.2 & $\mathrm{t}$ \\
\hline III+R3+StI & 396.5 & bcdefghıjk & $\mathrm{I}+\mathrm{P} \ddot{\mathrm{u}}$ & 304.0 & ghijklmno & $\mathrm{II}+\mathrm{Av}$ & 180.1 & $\mathrm{u}$ \\
\hline
\end{tabular}

$* \operatorname{LSD}=103,3$

Alev kaynaklı yanmada yanma sicaklığı; en yüksek I+R4, en düşük II+Av'de elde edilmiştir. Buna göre; alev kaynaklı yanmada yanma sıcaklığı artışı veya azalışında, renk açma çözeltisinin yanı sıra vernik çeşidi ve ağaç türünün de etkili olduğu söylenebilir. Ancak kontrol örneklerinin sıcaklık değerlerinin yüksek bulunması, işlemlerin yanma sıcaklığını azalttığı izlenimi vermektedir. Nitekim, renk açıcı kimyasal maddelerin sapsız meşe odununun yanma özelliklerine etkilerinin incelendiği çalışmada benzer sonuç elde edilmiştir (Özcifci, 2001). Araştırmaya ait grafik Şekil 2'de gösterilmiştir. 


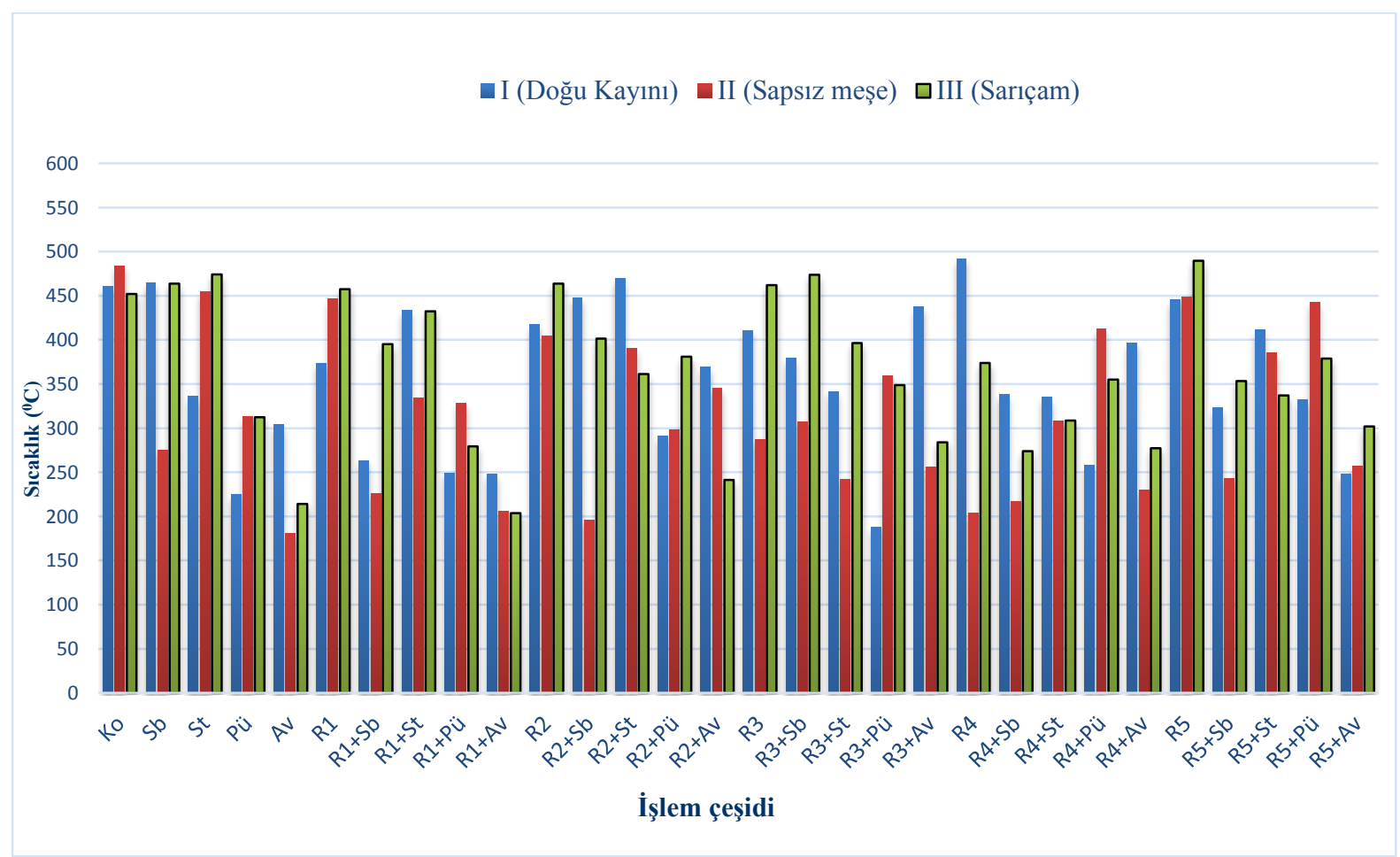

Şekil 2. Ağaç malzemelerde işlem çeşidine göre alev kaynaklı yanma sıcaklıkları

\section{Sonuçlar ve Öneriler}

- Verniklerde katman kalınlığ $1(\mu \mathrm{m})$; sentetik vernikte 92, poliüretan vernikte 120 , su bazlı vernikte 66, akrilik vernikte 128 ölçülmüştür. Vernik katman kalınlıkları arasında oluşan farklılık, verniklerin katı madde miktarından kaynaklanmış olabilir. Ayrıca katman kalınlığı yüzey düzgünlüğü arttıkça daha yüksek çıkmıştır. Elde edilen sonuçlar literatür ile uyumludur.

- Alev kaynaklı yanmada yanma sıcaklığı; en yüksek sarıçam, R1 ve sentetik vernikte, en düşük sapsız meşe, R3 ve poliüretan vernikte bulunmuştur. Alev kaynaklı yanma sıcaklığını vernikler ve R1 hariç azaltmıştır. Bu etki kontrol örneklerine göre, R2'de \%3, R3'de \%12, R4' de \%1 ve R5'de \%3 daha düşük gerçekleşmiş̧tir. Ağaç malzeme + renk açma çözeltisi etkileşiminde en yüksek; kayın+R1'de, en düşük meşe+R3'de, bulunmuştur. Ağaç malzeme + vernik etkileşiminde en yüksek; sarıçam + sentetik vernikte, en düşük meşe + su bazlı vernikte elde edilmiştir. Ağaç malzeme + renk açma çözeltisi + vernik etkileşiminde uygunluk; Kayın+R3+poliüretan vernik, meşe+R2+su bazlı vernik, sarıçam + R1+ akrilik vernik şeklinde olmuştur. Renk açma çözeltileri ağaç malzemenin yanma özelliklerinde etkili olmuş, bu etki çözelti çeşidine göre farklılık göstermiş, bu farklılıkta ağaç türünün de önemli etkisinin olduğu tespit edilmiştir. Bu durum, aynı çözeltinin farklı ağaçlarda farklı sonuçlar göstermesinden anlaşılmaktadır. Yangın riski yüksek olan yerlerde R3 çözeltisi bu bakımdan uygun olabilir.

- Bu sonuçlara göre; ağaç malzemenin yüzey özellikleri ile renk yeknesaklığı üzerinde önemli bir etkiye sahip olan renk açma maddelerinin, ağaç malzeme ile verniklerin yanma özellikleri üzerinde etkili oldukları ancak bu etkinin önem derecesinin düşük olduğu söylenebilir. Bunlara göre; renk açma işleminde, alev kaynaklı yanma özelliklerine etkileri bakımından uygunluk; ağaç malzeme bakımından Sapsız meşe odunu, renk açma çözeltisi bakımından R3 ve vernik bakımından akrilik vernik olduğu söylenebilir. Buna göre yangın riski söz konusu olan kullanım yerlerinde sapsız meşe+R3+Akrilik vernik kombinasyonu önerilebilir. 


\section{Teșekkür}

Bu çalışma, TÜBİTAK Bilimsel Araştırma Projeler Birimi tarafindan desteklenmiştir. Proje no: 2010 / 1090043.

\section{Kaynaklar}

ASTM E 160-50, (1975), Standart test method for combustible properties of terated wood by the crib test, ASTM Standards, USA

ASTM D 3023, (1998), Standard practice for determination of resistance of factory applied coatings on wood products to stains and reagents, ASTM Standards, USA

Aşc1 T., Keskin H., (2019), Combustion properties of Scots pine (Pinus sylvestris Lipsky) wood impregnated with boron compound doped colophony, Furniture and Wooden Material Research Journal, 2(1),11-22

Atar M., (1999), Renk açıcı kimyasal maddelerin ağaç malzemede üstyüzey işlemlerine etkileri, GÜ Fen Bilimleri Enstitüsü Doktora Tezi, Ankara

Bankowsky B., Eichletoer N., (1993), Raw materials for environment friendly wood lacquers, WKI-Bencht, Holer WorkingParty, For Wood Research, Brunswicle, 31, 145-157

Banks W.B., Miller E.R., (1982), Chemical Aspects of Wood Techology Sweden, Forest Products Journal, USA

Edwin P., Carter M., (1983), Wood bleaches and bleaching methods, finishing eastern, hard woods, U.S. Department of Agriculture, Forest Products Laboratory, Madison, 29, 39

Fidan M.S., Yaşar Ş., Yaşar M., Atar M., Alkan, E., (2016), Combustion characteristics of impregnated and surface-treated chestnut (Castanea sativa mill.) wood left outdoors for one year, BioResources 11(1), 2083-2095

Highley T.L., Kicle T.K., (1990), Biologuel degraation of wood, Phytopst Hology, 69, 11511157

Örs Y., Keskin H., (2008), Ağaç malzeme teknolojisi, Ders kitabı, Gazi Üniversitesi yayın no : 2000/352, Gazi yayınc1lık, Ankara

Özçifçi A., (2001), Renk açıcı kimyasal maddelerin sapsız meşe (Quercus sessiliflora salisb.) odununun yanma özelliklerine etkileri, Teknoloji Dergisi, 3(4), 63-72

SIGMA 74172 NSU., (2000), Baca gazı analizörü cihazı kullanım kılavuzu, İstanbul

Sönmez A., (1989), Ağaçtan yapılmış mobilya üst yüzeylerinde kullanılan verniklerin önemli mekanik fiziksel ve kimyasal etkilere karşı dayanıklılıkları, Gazi Üniversitesi Fen Bilimleri Enstitüsü Doktora Tezi, Ankara

TS 1476, (1984), Odunda fiziksel ve mekanik özelliklerin tayini için homojen meşçerelerden numune ağacı ve laboratuvar numunesi alınması, Türk Standartları Enstitüsü, Ankara

Yaşar Ş., Atar M., (2017), Ahşap koruyucularla muamele edilmiş bazı ağaç malzemelerin yanmasıyla ortaya çıkan gaz emisyon miktarları, Ileri Teknoloji Bilimleri Dergisi, 6(1), 503-514. 